\title{
PERCEPÇÃO DE PROFESSORES HOMENS SOBRE O MAL-ESTAR DOCENTE
}

\author{
LA PERCEPCIÓN DE PROFESORES HOMBRES ACERCA DEL MALESTAR \\ DOCENTE
}

PERCEPTION OF MALE TEACHERS ON TEACHER'S UNEASINESS

\author{
Josiane Peres GONÇALVES ${ }^{1}$ \\ Juan José Mouriño MOSQUERA ${ }^{2}$ \\ Claus Dieter STOBÄUS ${ }^{3}$
}

\begin{abstract}
RESUMO: Um dos problemas existentes entre os profissionais da educação refere-se ao fenômeno que passou a ser conhecido como mal-estar docente, surgindo o interesse em compreender esta realidade. Assim, o presente estudo tem por objetivo investigar as percepções de professores homens que escolheram o magistério como principal profissão, sobre o mal-estar docente. A pesquisa de natureza qualitativa foi realizada, por meio de entrevista semiestruturadas, com cinco professores do gênero masculino, cujas percepções predominantes são de que: as condições socioeconômicas, especialmente salariais, interferem nas condições de mal-estar docente; as relações interpessoais estabelecidas com os alunos são fatores que interferem nas condições de bem ou mal-estar dos professores; as situações de mal-estar docente são mais comuns entre as professoras mulheres.
\end{abstract}

PALAVRAS-CHAVE: Mal-estar docente. Homens professores. Gênero.

RESUMEN: Uno de los problemas existentes entre los profesionales de la educación se refiere al fenómeno que llegó a ser conocido como el malestar docente y el creciente interés en la comprensión de esta realidad. Así, el objetivo de este estudio es investigar las percepciones de los profesores varones que optaron por el Magisterio, como su principal ocupación, acerca del malestar docente. La investigación es de carácter cualitativo y se llevó a cabo, por medio de entrevistas semiestructuradas con cinco maestros hombres, cuyas las percepciones se caracterizan por: las condiciones socioeconómicas, especialmente acerca del sueldo, en que hay influencia en las condiciones del malestar docente; las relaciones interpersonales establecidas con los estudiantes son factores que interfieren en las condiciones para el bienestar o para el malestar de los maestros; las condiciones del malestar docente son más comunes entre las mujeres.

\footnotetext{
${ }^{1}$ Doutora em Educação pela Pontifícia Universidade Católica do Rio Grande do Sul. Professora do Programa de Pós-graduação em Educação pela Universidade Federal de Mato Grosso do Sul Campus do Pantanal (UFMS/CPAN). Líder do Grupo de Estudo e Pesquisa em Desenvolvimento, Gênero e Educação (GEPDGE). Naviraí - MS - Brasil. 79950-000 - josiane.peres@ufms.br

${ }^{2}$ Pós-doutor em Psicologia pela Universidad Autónoma de Madrid. Livre Docente em Psicologia da Educação. Professor Titular, Faculdade de Educação e de Letras da Pontifícia Universidade Católica do Rio Grande do Sul (PUCRS). Porto Alegre - RS - Brasil - 90619-900 - juan.mosquera@ pucrs.br ${ }^{3}$ Pós-doutor em Psicologia pela Universidad Autónoma de Madrid. Doutor em Ciências Humanas Educação. Professor Titular, Programa de Pós-Graduação em Educação, Programa de Pós-Graduação em Gerontologia Biomédica da PUCRS, Professor do Centro Universitário La Salle. Porto Alegre - RS Brasil - 90619-900 - stobaus@pucrs.br
} 
PALAVRAS CLAVE: Malestar docente. Profesores varones. Género.

ABSTRACT: One of the problems between the professional education refers to the phenomenon that became known as malaise teaching, emerging interest in understanding this reality. Thus, the present study aims to investigate the perceptions of male teachers who chose teaching as a main occupation on the malaise teacher. The qualitative research was conducted through semi-structured interviews with five male teachers, whose predominant perceptions are that: the socioeconomic conditions, especially wage interfere in the conditions of malaise teacher; interpersonal relationships with students are factors that affect the conditions of good or evil being of teachers; the teacher be evil situations are more common among women teachers

KEYWORDS: Teacher's uneasiness. Male teachers. Gender.

\section{Introdução}

O presente estudo é um recorte da tese da minha tese de doutorado, defendida na Pontifícia Universidade Católica do Rio Grande do Sul, sob a orientação do Professor Juan José Mourinõ Mosquera e co orientação do Professor Claus Stobäus, em que aborda questões relativas ao bem-estar docente. Considerando que para entender as situações inerentes ao bem-estar dos professores se faz necessário compreender também a situação oposta, inicialmente foi realizado um levantamento sobre estudos relativos ao mal-estar docente, conforme apresentamos neste estudo.

A pesquisa de campo da tese de doutorado foi realizada com cinco professores do gênero masculino com idades entre 28 a 64 anos, com experiência profissional tanto na docência da educação básica, quanto na docência do ensino superior. As percepções desses homens em relação ao mal-estar docente e como eles se viam diante dessa realidade, complementam os dados do presente estudo, conforme apresentados logo após a revisão da literatura.

\section{Estudos teóricos sobre o mal-estar docente}

Um dos primeiros estudos a abordar a temática inerente ao mal-estar docente foi realizado por Esteve (1999), que procurou analisar a evolução da saúde de todos os professores de EGB e de EE.MM em Málaga, na Espanha, através do mapeamento das licenças médicas oficiais durante um período de sete anos (1982-1989). Na fase inicial da pesquisa, a amostra era composta por 6.483 docentes, havendo 425 registros de licença, e, na fase final, havia 8.312 professores, com 1.346 registros de licença. $\mathrm{O}$ autor reconhece que aumentou o número de professores, “[...] mas ainda que se considerem 
essas cifras, o aumento de licenças é muito superior, mais que o dobro, ao aumento que corresponderia à ampliação da amostra de professores" (ESTEVE, 1999, p. 93).

A faixa etária média dos professores em licença era de 40 anos, evidenciando que o índice é maior entre aqueles que se encontravam na fase final da carreira profissional. Quanto ao gênero, Esteve (1999) percebeu que as mulheres apareciam significativamente mais afetadas pelas licenças médicas $(7,86 \%-20,9 \%)$, sem contar as licenças-maternidade, se comparadas aos homens $(4,92 \%-10,97 \%)$. A tendência maior no grupo feminino se mantinha nas diferentes causas das licenças médicas, com exceção das doenças digestivas e cardiovasculares, que apareciam com maior incidência no grupo masculino.

O autor procurou analisar também os ciclos de stress e a sua relação com as licenças médicas, destacando que havia um aumento das licenças no início do trimestre, até que um período de férias interrompia o ritmo de acumulação da tensão, reduzindo o número de afastamento de professores do ambiente de trabalho.

Os resultados deste estudo foram publicados por Esteve (1999) na obra "O MalEstar Docente: a sala de aula e a saúde dos professores", popularizando o termo "malestar docente". O autor explica que costuma usar esta expressão para descrever os efeitos contínuos de caráter negativo que afetam a personalidade do professor, como resultado das condições psicológicas e sociais em que se exerce a docência. Ressalta que a enfermidade tem sintomas manifestos, mas o mal-estar caracteriza-se por sensação de que algo não está bem, sem, no entanto, haver uma causa explícita para este sentimento. Conceitua o mal-estar docente como sendo os comportamentos que expressam insatisfação profissional, elevado nível de stress, absentismo, falta de empenho em relação à profissão, desejo de abandonar a carreira profissional, podendo, em algumas situações, resultar em estados de depressão.

Outros países, como Portugal e Brasil, passaram também a se preocupar com esta temática, para que, compreendendo melhor o fenômeno inerente ao mal-estar docente, pudessem investir tanto em prevenção quanto na promoção do bem-estar dos professores.

Em Portugal, Jesus (1998) destaca-se entre os pesquisadores que têm trabalhado sobre esta temática e, seguindo a mesma linha de pensamento de Esteve (1999), compreende que o conceito de mal-estar docente é um fenômeno que sofre influência de fatores sociopolíticos, pessoais e da formação profissional. Reconhece que as mudanças sociais que ocorreram, especialmente na segunda metade do século $\mathrm{XX}$, influenciaram a 
educação e contribuíram para a desvalorização do papel do professor. Entre outras mudanças, Jesus (1998) destaca:

a) era da informação - no passado a transmissão de conhecimentos era atribuída ao professor, atualmente a mídia e a internet, entre outros, assumiram também esta função.

b) democratização do ensino - a escola passou a ser obrigatória, aumentou o número de alunos e também de professores, porém a formação docente não correspondia às necessidades e muitos entraram para a área da educação mesmo sem a identificação pessoal com a profissão docente.

c) novas exigências - além da aquisição constante de novos métodos e de novas técnicas de ensino, o professor assume também a função educativa que antes era da família, e ainda se responsabiliza por: atividades extraclasses, reuniões, preparação de aulas, correção de atividades e avaliações de alunos, entre outras.

d) falta de materiais - nem sempre é possível concretizar o almejado, visto que as salas muitas vezes são lotadas, com poucos recursos físicos e materiais, além da falta de investimento na formação docente.

e) salário - outras áreas ou profissões com o menor ou igual nível de formação costumam ganhar muito mais que o professor, refletindo no próprio status da profissão docente.

Podemos observar que várias mudanças ocorreram na sociedade e, consequentemente, no âmbito escolar, que acabaram por interferir no trabalho e na vida pessoal dos professores, resultando num estado de mal-estar docente. Isto nos leva a crer que a promoção do bem-estar dos professores também passa por iniciativas amplas, no sentido de atribuir maior valor a esse trabalho, que é tão imprescindível para toda sociedade.

Assim como nos países europeus, no Brasil esta temática passou a ser vista como um problema que carecia de mais estudos pelos pesquisadores, sendo que um dos primeiros trabalhos, intitulado "O Mal-Estar na Docência: causas e consequências", foi publicado por Stobäus e Mosquera (1996), abrindo caminhos para que outros estudos fossem realizados na área. Para os referidos autores, o mal-estar docente tem causas diversas e resulta em situações angustiantes para os profissionais da educação, sendo necessária a implementação de medidas que possam ajudar a amenizar esta situação. Para Mosquera (2000, p. 38), “O docente colocado na encruzilhada dos paradoxos pósmodernos, tais como a globalização, o final das certezas, o mosaico móvel da cultura e a 
necessidade de afirmação de si mesmo, encontra-se ante uma angustiante problemática". É evidente que esta realidade complexa resulta em situação de mal-estar pessoal e de mal-estar docente, refletindo no desempenho do seu trabalho.

Estas análises foram importantes para que outros trabalhos surgissem na área, especialmente como resultados de pesquisas dos cursos de mestrado e de doutorado existentes no país. Ao fazer uma busca no banco de teses e de dissertações da CAPES sobre os trabalhos que, no título, apresentassem a expressão "mal-estar docente", foi possível constatar que vários estudos já foram concluídos (COSTA, 2001; CARVALHO, 2003; LEÃO, 2003; NOAL, 2003; SOUZA FILHO; 2003; OLIVERIA, 2005; BERANGER, 2007, ANSELMO, 2011. DOHMS, 2011; KEHL, 2011; LVES, 2011; PEREIRA, 2011; SENNA, 2011; VIEIRA, 2011; WEBBER, 2011; MAZON, 2012; OLIVEIRA, 2012; SAMPAIO, 2012; VIEIRA, 2012), sabendo-se que outros devem estar em andamento.

Estes dados indicam que a comunidade científica está se sensibilizando em prol da situação angustiante pela qual têm passado os profissionais da educação. E, apesar de considerar a relevância destes estudos já realizados, acredito que é importante que novos estudos avancem ainda mais, principalmente no sentido de buscar alternativas que possam contribuir com o bem-estar das/os professoras/es.

\section{Metodologia}

Participaram desta pesquisa, de natureza qualitativa com a utilização de entrevista semiestruturada, cinco homens professores que escolheram o magistério como principal profissão e passaram pela experiência de atuar em diversos níveis de ensino, em instituições públicas e particulares. Para efeito de organização textual e visando manter o sigilo da identidade dos participantes, eles foram identificados pelos caracteres P1, P2, P3, P4 e P5.

Entre os entrevistados, um estava na faixa dos 30 anos, dois estavam na faixa etária de 30 a 40 anos, um estava se aproximando dos 60 anos e um estava na faixa etária dos 60 e 70 anos. Ou seja, quatro deles eram considerados adultos de meia idade e um já poderia ser considerado idoso, segundo Papalia (2006).

Uma característica marcante refere-se ao curso de graduação com predominância para a área de Ciências Humanas e mais especificamente para o curso de Filosofia, já que três deles foram seminaristas, sendo este um fator decisivo para a 
escolha do curso superior e, consequentemente, para a escolha da profissão. Entre os cinco docentes, um era doutor, três eram mestres e um era especialista. As entrevistas foram agendadas com antecedência e gravadas nas casas dos participantes ou em seus ambientes de trabalho.

\section{Resultados e Discussões}

O fenômeno inerente ao mal-estar docente é atual, visto que, no passado, a sociedade tinha outra forma de valorização do professor, que era considerado o detentor do saber. Como nem todas as pessoas tinham acesso à educação, o professor, que tinha um nível mais elevado de escolaridade, se comparado com a maioria da população, era bem visto pela sociedade, por exercer uma profissão que tinha um status reconhecido socialmente (SOLOMON, 1998).

Não faz muito tempo que esta situação mudou, uma vez que no final da década de 1960, quando o P4 começou a trabalhar, "o professor tinha muita consideração da sociedade" e "a família se orgulhava de ter um professor". Neste período, "o professor era valorizado, independente do grau de ensino" e, em regiões do interior do país, "ele era uma referência na cidade."

Poderíamos nos questionar o motivo por que tão rapidamente esta realidade mudou a ponto de um professor não ter o mesmo reconhecimento perante a sociedade. Segundo a opinião do P1, "a sociedade em geral valorizava muito o professor quando ele era um vocacionado...", mas atualmente a realidade é outra: "Eu sempre via, no final do ensino médio, que muitos alunos não tinham condições de passar num curso concorrido [...] então ele acabava optando pelas carreiras ligadas ao magistério, já que é mais baixa a concorrência."

O professor considera que as consequências sobre esta escolha podem ser graves, resultando em situações de mal-estar docente. "O problema é que quando você tem um professor frustrado, que era pra ser engenheiro, entrando na sala de aula, um professor que era pra ser médico entrando na sala de aula... as coisas ficam difíceis."

Ele cita ainda o fato de algumas pessoas se perceberem incompetentes para trabalhar em outras áreas, ou terem receio de recomeçar numa outra carreira, e, diante disso, continuam no magistério, apesar de não realizarem um bom trabalho e de se sentirem frustradas na profissão. 
Podemos notar que o professor atribui, em grande parte, as causas para o malestar docente ao próprio professor, que, por fazer uma escolha errada da carreira profissional, sente-se insatisfeito ou desmotivado para desenvolver a sua função.

Outro entrevistado que também atribuiu o problema principalmente à figura do professor é o P3, que disse: "O que causa o maior estresse, eu percebo em relação ao professor, é exatamente a insegurança em relação ao conteúdo, é desenvolver uma atividade que o aluno não gosta..." E o próprio professor indaga: "Então o que é o malestar?" e, em seguida, responde: “É você estar dentro de uma sala de aula e perceber que o aluno não está gostando do seu trabalho, acho que isso que causa o maior mal-estar."

Ele comenta sobre os casos dos professores que precisam usar outros artifícios para chamar a atenção do aluno, como é o caso da avaliação, e enfatiza que isto resulta em mal-estar tanto para o professor quanto para os alunos. O P1 também comentou sobre o problema de usar a avaliação como uma ameaça para fazer o aluno ficar quieto e até fez uma brincadeira para entender a gravidade da situação: "Nós sabemos de professores que pegaram a prova do aluno e deu aquele sorrisinho de canto de boca, porque a nota foi baixa." Então ele refletiu: "Qual médico que chega pro seu paciente e fala assim ‘já que você vai morrer...' ou 'você está morrendo' e dá uma risada?" E conclui: "Quer dizer, eu acho que esse é o nosso maior problema."

Em relação à avaliação, Esteve (2005) comenta sobre as distorções na definição do papel do professor que precisam ser evitadas, sendo que uma delas diz respeito às práticas avaliativas, que transformam o professor num seletor natural. $\mathrm{O}$ autor compreende que, quando o professor não consegue ter um encaminhamento metodológico que atenda às necessidades da turma, ele passa a usar a avaliação como forma de punição ou para manter o domínio da turma. Quando, na verdade, deveria haver uma boa relação entre professor e aluno sem ter a necessidade de usar erradamente outros artifícios, como a avaliação, por exemplo, para amedrontar a turma, transformando-se num seletor natural.

No caso dos relatos dos dois professores (P1 e P3) foi possível perceber que atribuem as causas do mal-estar docente principalmente a fatores pessoais, por escolher erradamente a profissão, por não estar bem preparado para ensinar, por não conseguir cativar a turma de alunos, entre outros. Nesse sentido, Jesus (1998) menciona que o mal-estar docente pode ocorrer devido a fatores pessoais, sociais e da formação profissional. Existem diversos fatores sociais que influenciam no surgimento do fenômeno entendido como mal-estar docente, mas também existem fatores pessoais: 
apesar de atuar todos no mesmo contexto, enquanto alguns estão satisfeitos com a profissão, outros se sentem frustrados, evidenciando que a forma como cada um compreende o processo educativo resulta em situações de bem- ou de mal-estar docente.

Se o P3 comentou sobre a boa relação com o aluno e que cabe ao professor criar meios para que os discentes se interessem pela aula, o P2 disse o oposto, pois mencionou que muitos alunos não se comprometem com o ensino e isto resulta em estados de mal-estar docente.

\begin{abstract}
A pressão é que vem causando danos à saúde, estresse, desgaste emocional... A liberdade legal que se dá ao aluno, os direitos que se dão ao aluno... Historicamente falando, a gente vê que hoje o aluno tem muito mais respaldo legal e o professor menos respaldo legal que se tinha na última ou penúltima geração. Então o problema de saúde do professor vem aumentando. Então, até ao nível de rede pública também, ao que se ouve é que têm muitos professores com problema de voz, com problema de depressão profunda, inclusive devido ao desgaste emocional causado pela sala de aula.
\end{abstract}

Para Jesus (1998), com a democratização do ensino, a escola passou a ser obrigatória para todos, aumentando o número e a diversidade de alunos, tornando-se mais difícil o processo de ensino, principalmente para os professores pouco qualificados. Paralelamente, a família foi deixando algumas atribuições educativas para a escola e deixou de impor limites, resultando numa geração de estudantes que sabem dos seus direitos, mas não têm noção dos deveres, inclusive no que se refere ao respeito à pessoa do professor.

Todas estas mudanças de ordem social influenciam o processo de ensino, resultando em situações de mal-estar docente. Além dos problemas citados pelo P2 sobre os fatores sociais, existem outros que também interferem na forma como o professor se sente em relação à sua profissão. Alguns deles foram citados pelo P4, que afirmou: "Os fatores que provocam o mal-estar do professor passam pela desvalorização, passam pelos planos de saúde, passam pelos programas econômicos da família..." O professor também comentou a respeito das questões de gênero caracterizadas pela predominância de mulheres atuando no magistério.

[...] uma grande maioria é professora, a professora chega na sala de aula com uma carga muito grande de responsabilidade. Na família muitas vezes não há esse compartilhamento de responsabilidades, então a mulher, principalmente, ela carrega mais esta insatisfação, o estresse pelo tempo de trabalho [...] 
Fiquer (2006), ao analisar as relações existentes entre bem-estar e gênero, percebeu que, na maioria dos estudos, ou não há diferença significativa ou as mulheres evidenciam possuir níveis mais elevados de mal-estar. Em nenhum deles os homens apresentavam maiores níveis de mal-estar do que as mulheres, evidenciando que, apesar de os estudos empíricos ainda serem insuficientes, eles indicam que as mulheres tendem a apresentar maiores níveis de insatisfação se comparadas com os homens.

Se considerarmos que no magistério há a prevalência de mulheres, podemos concluir que se trata de um público que costuma apresentar uma incidência maior de mal-estar e que, ao assumir uma função tão complexa, pode resultar em estados ainda maiores de mal-estar docente.

Também Gonçalves (2008), ao fazer um estudo sobre o mal-estar docente e gênero, constatou que os homens, mais que as mulheres, se encontravam em situação de bem-estar, devido à sobrecarga de trabalho assumida pelas professoras. Sendo assim, os estudos parecem indicar que está correta a análise feita pelo P4 sobre o mal-estar docente e predominância de mulheres no magistério.

Outra situação citada pelo referido professor diz respeito aos docentes que estão em fase final da carreira profissional. "É muito comum você ouvir dizer que professores quando chegam próximo da fase de aposentadoria, em vez de serem mais produtivos pela experiência que têm, são mais acomodados porque não veem a hora de sair da escola." Em contrapartida, normalmente estas pessoas acabam voltando para a profissão. "Se for feito uma pesquisa com esses professores que saem da escola, num momento seguinte eles fazem de tudo para poderem retornar pra escola." Diante deste contexto, o P4 entende que são os fatores sociais que provocam o mal-estar docente, mas não somente eles, pois se trata de fatores bem diversificados: "Então isso prova pra mim que não é o fato de ser professor que causa esse mal-estar, mas as condições que cercam, que são condições econômicas, condições de saúde, condições da família, burocracia, né?"

Para Esteve (1999), nos últimos anos houve várias mudanças que resultaram em condições de mal-estar, como, por exemplo: a falta de materiais, os baixos salários, a era da informação, as novas exigências educacionais, entre outras. No caso das exigências, o autor comenta sobre as novas atribuições que o professor passou a assumir como a função educativa (que antes era da família), e ainda se responsabiliza por: atividades extraclasse, reuniões, preparação de aulas, correção de atividades e avaliações de alunos, além de outras atividades. Também Stobäus e Mosquera (1996) 
afirmam que o mal-estar docente tem causas diversas, resultando em situações angustiantes para os profissionais da educação, sendo necessária a implementação de medidas que possam ajudar a amenizar esta situação.

No caso do P5, ele compreende que os fatores que contribuem para o mal-estar docente também são sociais, especialmente relacionados às questões salariais, mas entende que, em parte, os docentes têm responsabilidade, por entender que "muitos dos professores sindicalizados, no momento em que o sindicato assume uma posição, não se fazem presentes, para reivindicar junto com o sindicato a questão salarial. Eles têm um pouquinho de culpa no cartório."

$\mathrm{O}$ professor se refere à participação do professor na luta por melhores condições de trabalho. Embora seja verdade que a profissão docente tem muito o que melhorar, também é verdade que muitas conquistas foram obtidas através de reivindicações dos professores através de sindicatos. É preciso que haja iniciativas governamentais, mas o professor também deve ser sujeito deste processo, na busca por melhores condições de trabalho.

O P5 ainda relatou que "os professores que ganham pouco, assumem uma postura de 'dador de aula', isso é um pecado capital porque nós não podemos ir para uma sala de aula achando que vamos 'dar' uma aula..." O professor compreende que o momento em que está em sala de aula é um momento único, de grandes encontros, é muito mais do que apenas dar aula. "Nós vamos para um encontro de ensino aprendizado, esse encontro tem que ser bem resolvido e não deve estar em questão o nosso salário [...] Na sala de aula os nossos alunos não têm nada a ver se nós ganhamos pouco ou ganhamos muito."

Assim, o P5 falou sobre a importância de se refletir sobre a prática docente como uma forma de evitar situações de mal-estar, indo ao encontro do que diz Nóvoa (1995), sobre o professor reflexivo, que reflete sobre a sua prática, que pensa e que elabora em cima dessa prática. Trata-se de uma experiência importante, que inclui uma análise individual e também coletiva através da participação com os colegas tanto nas escolas quanto num contexto de formação docente. Neste processo de reflexão, os envolvidos tornam-se sujeitos do processo de formação em que todos ensinam e aprendem com as próprias experiências e com aquelas vivenciadas por outros colegas ou educadores. 
Se a gente não consegue fazer essa reflexão da nossa ação pedagógica, da nossa ação docente, da nossa ação cotidiana, a gente começa se frustrar, a nossa autoestima começa a baixar, daí eu começo a não sentir bem naquilo que faço, daí meu aluno é um pentelho, meu aluno é marginal, meu aluno é tudo aquilo que eu deveria estar trabalhando para que ele não fosse. (P5)

Da mesma forma em que anteriormente o P3 havia comentado sobre a preocupação com o aluno, e se o professor se encontra em situação de mal-estar, o aluno é o maior prejudicado. O P5 demonstra esta mesma preocupação, porque a contribuição social do professor é evidenciada pelos alunos que foram educados por ele através de um processo de inclusão escolar e social.

Meu aluno não pode ser aquilo que eu possa imaginar se eu não o desejo comigo. Ao contrário, ele tem que ser alguma coisa, algum ingrediente, aquela peça do tabuleiro [...] ele tem que ser incluído continuamente porque a maior barbárie que uma instituição de ensino pode estar cometendo é ser o elemento principal de exclusão do aluno, quando ela deveria ser sempre inclusiva.

Em relação a este assunto, Esteve (2005) comenta que o professor deveria compreender que a essência do seu trabalho é estar a serviço da aprendizagem dos alunos, que, sem a presença e evolução desse aluno, o trabalho docente perde o sentido. Diante disso, poderíamos afirmar que a questão do mal-estar docente é muito séria, porque, além de o professor não estar bem, outras pessoas são influenciadas negativamente, refletindo no resultado do processo de ensino e aprendizagem dos alunos.

Outra situação interessante que pude perceber durante a realização da pesquisa é a de que todos os professores afirmaram que se encontravam em situação de bem-estar docente e, de fato, demonstraram esta característica através dos seus relatos. E já era de se imaginar que aqueles profissionais que são considerados bem-sucedidos estariam, sim, em situação de bem-estar docente.

Um caso específico ocorreu, porém, que, embora afirmando que sim, através de outros relatos foi possível perceber que, temporariamente, se encontrava em situação de mal-estar docente. Trata-se do P2, que vinha passando por algumas situações na sua vida pessoal e profissional. Conforme foi relatado num outro momento, durante o período de realização das entrevistas, o professor estava passando pela experiência de ser pai pela segunda vez, a esposa havia reduzido a carga horária de trabalho e, 
consequentemente, o salário, além de que a faculdade onde o professor trabalhava vinha passando por intensas mudanças que resultaram na redução de carga horária de trabalho.

Todo este contexto, que não pode ser aqui desconsiderado, influenciou negativamente a vida do professor, que, apesar de ser considerado bem-sucedido, vinha passando por uma situação atípica. Verbalmente ele disse: "Eu me sinto em condição de bem-estar docente porque eu gosto do que eu faço. Quando eu vou alimentar o meu currículo eu me sinto bem porque eu percebo uma certa evolução da minha produção acadêmica."

Em outros momentos, porém, ele fez diversas reclamações em relação à profissão e, ao ser questionado se escolheria ser professor novamente se pudesse escolher a profissão, o professou não hesitou em afirmar:

Eu iria pensar duas vezes pelo fator financeiro, porque hoje pela pouca valorização salarial, no $15^{\circ}$ ano de profissão, eu tenho que trabalhar muito mais do que no $1^{\circ}$ pra compensar, pra ter uma equivalência de renda e isso não é uma questão minha, é questão familiar. Então pra manutenção da vida familiar e pra um padrão médio de vida é preciso dinheiro. Então eu iria pensar duas vezes pra continuar no magistério. No entanto, é provável que eu escolhesse de novo essa profissão pela paixão pela ciência, como eu falei.

O professor também comentou, e de certa forma fez um desabafo, sobre a falta de tempo para se organizar, por trabalhar de segunda- a sexta-feira em cursos de graduação e ensino médio, e, aos sábados, em cursos de pós-graduação. Isto provoca um cansaço, resultando em insatisfação. Nesse sentido, ele faz comparativos com profissionais de outras áreas e conclui que, em outras, a situação é mais tranqüila, é diferente da profissão docente.

Eu vejo colegas de outras profissões que trabalham, por exemplo, das 08:00 as 18:00 horas no seu ambiente de trabalho, mas em casa têm tempo integral. Mas na nossa profissão ela tem antes, o durante e o depois; que é preparar, desenvolver a aula e corrigir a avaliação. Então isso tem desgastado bastante. Então eu tenho tido dificuldades para administrar nesse aspecto.

Toda esta situação vivenciada pelo P2 nos vem mostrar que, ao longo da carreira profissional, todas as pessoas estão sujeitas a passar por fases difíceis e ficar na dúvida se estão na profissão certa. O que não significa que a pessoa não seja um profissional competente. No caso do professor entrevistado, ficou bem evidente que diversos fatores acontecidos recentemente resultaram num estado de mal-estar docente temporário. 
De acordo com Timm (2006), a condição de sentir bem- ou mal-estar na docência nunca será definitiva e implica sentimento e vivência de prazer e de desprazer. "São, portanto, condições que podem ser alteradas, pois que geradas pela maior ou menor aquisição de prazer e pela maior ou menor diminuição de desprazer naquilo que se faz.” (p. 16)

Assim, pelo fato de o P2 encontrar-se, na época da entrevista, em situação de mal-estar, isso não significa que esse mal-estar será eterno, mas que, possivelmente, ele deverá superar os problemas e continuar desenvolvendo o seu trabalho com a mesma competência que sempre teve, e, o melhor de tudo, encontrar um novo estado de bemestar docente.

Para Lapo (2005), o mal-estar docente está relacionado com as interpretações que o sujeito faz da realidade, sendo que a sua subjetividade faz com que tenha avaliações positivas ou negativas sobre o seu contexto de trabalho, podendo resultar em situações de bem- ou mal-estar docente. Se, por ventura, for percebido que predomina o mal-estar, a pessoa precisa buscar formas de resolver a situação, para que novamente atinja um nível de bem-estar, que será importante para ele mesmo e para as pessoas que fazem parte do seu convívio social.

\section{Considerações Finais}

Considerando a finalidade do presente estudo que consiste em investigar as percepções de professores do gênero masculino sobre o mal-estar docente, por meio da análise da literatura percebemos que o fenômeno conhecido como mal-estar docente começou a ser estudado na Espanha, Portugal e posteriormente no Brasil mediante as pesquisas de Mosquera e Stobäus. Na atualidade, o banco de teses e dissertações da Capes apresenta diversos estudos nacionais que evidenciam a seriedade desse problema na sociedade brasileira.

Por meio da pesquisa de campo, realizada com cinco professores homens, podemos constatar que as percepções predominantes são de que fatores econômicos e sociais, especialmente relativos à questão salarial e exigências do trabalho, resultam em situações de mal-estar docente. As relações interpessoais estabelecidas com os alunos destacam-se como fatores que interferem tanto para as questões de mal-estar, quanto de bem-estar. Se por ventura predomina as relações saudáveis, em que o professor percebe que os alunos gostam da disciplina, aprendem e se comprometem com as atividades 
educativas, resulta em situações favoráveis. Ao contrário, se há o descaso por parte dos alunos, falta de compromisso e desrespeito em relação à figura do professor, resultam em situações desfavoráveis, configurando-se assim condições de mal-estar docente.

Também as questões de gênero se tornaram presentes, uma vez que os entrevistados acreditam que as professoras mulheres é que evidenciam mais situações relativas ao mal-estar. Estudos sinalizam que o fato de a mulher ter sobrecarga de trabalho, inclusive em âmbito familiar, e não ter tempo para si ou para o lazer compromete o seu bem-estar e consequentemente essa condição se reflete na escola.

Entendemos que a situação de mal-estar docente continua sendo um problema grave no Brasil que carece de novos estudos na área e especialmente de iniciativas governamentais que visem resolver esse problema, a fim de que os professores atinjam situações caracterizadas como bem-estar docente.

\section{REFERÊNCIAS}

ANSELMO, A. C. Psicanálise e educação: o mal-estar do professor universitário na atualidade. 2011. 97 f. Dissertação (Mestrado em Psicologia) - Faculdade de Educação, UFPR, Curitiba, 2011.

BERANGER, M. Profissionalidade e identidade profissional do professor de matemática: o fenômeno do mal-estar docente e suas implicações. 2007. $83 \mathrm{f}$. Dissertação (Mestrado em Matemática) - Faculdade de Matemática, PUCSP, São Paulo, 2007.

CARVALHO, F. A. O mal-estar docente: das chamas devastadoras (burnout) às flamas da esperança-ação (resiliência). 2003. 248 f. Dissertação (Mestrado em Psicologia da Educação) - Faculdade de Educação, PUCSP, São Paulo, 2003.

COSTA, F. T. L. Implicações do mal-estar docente: estudo comparativo entre professores e professoras da Universidade de Cruz Alta. 2001. 115f. Dissertação (Mestrado em Educação) - Faculdade de Educação, UFSM, Santa Maria, 2001.

DOHMS, K. P. Níveis de mal/bem estar docente, de autoimagem e autoestima e de autorrealização de docentes em uma escola tradicional de Porto Alegre. 2011. 112 f. Dissertação (Mestrado em Educação) - Faculdade de Educação, PUCRS, Porto Alegre, 2011.

ESTEVE, J. M. Bem-estar e saúde docente. Revista PRELAC-UNESCO, Santiago: ano I, n. 1, p. 116- 133, jul. 2005.

ESTEVE, J. M. O mal-estar docente: a sala de aula e a saúde dos professores. Trad. Durley Cavicchia. Bauru: EDUSC, 1999. 
FIQUER, J. T. Bem-estar subjetivo: influência de variáveis pessoais e situacionais em auto-relatos de afetos positivos e negativos. 2006. 158 f. Dissertação (Mestrado em Psicologia) - Instituto de Psicologia, USP, São Paulo, 2006.

GONÇALVES, C. M. M. M. Escola pública: bem-estar docente, mal-estar docente e gênero. 2008. 120f. Dissertação (Mestrado em Educação) - Faculdade de Educação, PUCRS, Porto Alegre, 2008.

JESUS, S. N. Bem-estar dos professores: estratégias para realização e desenvolvimento profissional. Porto Codex - Portugal: Porto Editora, 1998.

KEHL, U. Bem-estar e mal-estar dos professores no colégio Marista Pio XII de Novo Hamburgo. 2011. 90 f. Dissertação (Mestrado em Educação) - Faculdade de Educação, PUCRS, Porto Alegre, 2011.

LAPO, F. R. Bem-estar docente: limites e possibilidades para a felicidade do professor no trabalho. 2005. 160 f. Tese (Doutorado em Educação) - Faculdade de Educação, USP, São Paulo, 2005.

LEÃO, C. B. M. Entre o bem e o mal-estar docente: um retrato de professores do ensino superior privado. 2003. 100 f. Dissertação (Mestrado em Educação) - Faculdade de Educação, UEPG, Ponta Grossa, 2003.

LVES, A. L. A formação continuada como viés de bem / mal-estar docente. 2011. 102 f. Dissertação (Mestrado Profissional em Inclusão Social e Acessibilidade) FEEVALE, São Paulo, 2011.

MAZON, C. C. X. O mal-estar docente em gestores escolares. 2012. 69 f. Dissertação (Mestrado em Psicologia do Desenvolvimento e Aprendizagem) - UNESP, Bauru, 2012.

MOSQUERA, J. M. M. Pós-modernidade, cultura e professorado: uma análise da subjetividade docente. Educação-PUCRS, Porto Alegre, ano XXIII, n.41, p.31-46, ago. 2000.

NOAL, I. Manifestações do mal-estar docente na vida de professoras do ensino fundamental: um estudo de caso. 2003. 203f. Dissertação (Mestrado em Educação) Faculdade de Educação, UFSM, Santa Maria, 2003.

OLIVEIRA, C. A. V. Formação de professores: identidade e "mal-estar docente". 2005. 150 f. Dissertação (Mestrado em Educação) - Faculdade de Educação, UNESP, Presidente Prudente, 2005.

OLIVEIRA, R. R. Educação integral: cartografia do mal-estar e desafios para a formação docente. 2012. 212 f. Tese (Doutorado em Educação) - Faculdade de Educação, UNB, Brasília, 2012.

PAPALIA, D. Desenvolvimento humano. 8. ed. Porto Alegre: Artmed, 2006. 
PEREIRA, F. F. S. Indicadores de mal-estar docente em escolas públicas municipais de salvador. 2011. 121 f. Dissertação (Mestrado em Educação) - Faculdade de Educação, UFBA, Salvador, 2011.

SAMPAIO, D. T. O mal-estar no trabalho de professoras das séries iniciais do ensino fundamental de porto velho. 2012. $174 \mathrm{f}$. Dissertação. (Mestrado em Psicologia) - UNIR, Porto Velho, 2012.

SENNA, L. B. Do mal-estar ao bem-estar docente: uma análise de caso Argentina e Brasil. 2011, 135 f. Dissertação (Mestrado em Educação) - Faculdade de Educação, PUCRS, Porto Alegre, 2011.

SOLOMON, J. Desenvolvimento profissional de professores: prática evolucionária, reforma curricular e mudança cultural. Educar, Curitiba, n. 14, p. 137-150, 1998.

SOUZA FILHO, O. C. O professor de medicina no contexto do mal-estar docente. 2003. 74 f. Dissertação (Mestrado em Educação) - Faculdade de Educação, UFSM, Santa Maria, 2003.

STOBÄUS, C. D.; MOSQUERA, J. J. M. O mal-estar na docência: causas e consequências. Educação-PUCRS, Porto Alegre: ano XIX, n. 3, p. 139- 146, set. 1996.

TIMM, E. Z. O bem-estar na docência: dimensionando o cuidado de si. 2006. 262 f. Tese (Doutorado em Educação) - Faculdade de Educação, PUCRS, Porto Alegre, 2006. VIEIRA, A. S. A escola que adoece: o professor, suas condições de trabalho e o mal-estar docente. 2012. 137 f. Dissertação (Mestrado em Educação) - Faculdade de Educação, UFF, Niterói, 2012.

VIEIRA, M. L. Mal-estar docente e sofrimento psíquico: ocaso de professores de uma escola da rede municipal de Uberaba, MG. 2011. 173 f. Dissertação (Mestrado em Educação) - Faculdade de Educação, UNIUBE, Uberaba, 2011.

WEBBER, D. V. Profissão professor - desafios e possibilidades do direito ambiental laboral frente ao mal-estar docente. 2011. 186 f. Dissertação (Mestrado em Direito) - UCS, Caxias do Sul, 2011.

\section{Como referenciar este artigo}

GONÇALVES, Josiane Peres Gonçalves; MOSQUERA, Juan José Mouriño; STOBÄUS, Claus Dieter. Percepção de professores homens sobre o mal-estar docente. Revista Ibero-Americana de Estudos em Educação, Araraquara/SP, v. 11, n. 4, p. 2125-2140, 2016. Disponível em: 〈http://dx.doi.org/10.21723/riaee.v11.n4.8230>. EISSN: 1982-5587.

Submetido em: novembro/2015

Aprovação final em: outubro/2016 
